\title{
PERFORMANCE OF MOV ARRESTERS DURING VERY CLOSE, DIRECT LIGHTNING STRIKES TO A POWER DISTRIBUTION SYSTEM
}

\author{
M.I. Fernandez \\ Student Member, IEEE
}

\author{
K.J. Rambo \\ Non-Member \\ Department of Electrical and Computer Engineering \\ University of Florida \\ Gainesville, FL USA
}

\author{
M.A. Uman \\ Fellow, IEEE
}

\begin{abstract}
In 1996, at the International Center for Lightning Research and Testing (ICLRT) at Camp Blanding, Florida, the responses of MOV arresters in an unenergized test distribution system, composed of an overhead line, underground cable, and padmount transformer with a resistive load, were measured during very close, direct lightning strikes to the overhead line. Arresters were installed on the overhead line at two locations $50 \mathrm{~m}$ apart (on either side of the strike point) and at the primary of the padmount transformer which was connected to the line via the underground cable. We obtained arrester data for this test configuration from two lightning flashes (containing a total of five strokes) which were artificially initiated from a natural thunderstorm, using the rocketand-wire technique. We present the simultaneously-recorded arrester discharge current and voltage waveforms from one lightning stroke for one of the two arresters on the line and for the arrester at the transformer primary. Additionally, we estimate the energy absorbed by the arrester on the line as a function of time for the first $4 \mathrm{~ms}$ of the lightning event. The records presented are representative of those for all five strokes.
\end{abstract}

Keywords: Lightning, MOV Arresters

\section{INTRODUCTION}

Surge arresters are an important means of lightning protection in distribution systems. Perhaps surprisingly, few studies have been conducted to investigate the response of distribution arresters to actual lightning-surge conditions.

In 1978, a project was sponsored by the U.S. Department of Energy to study the responses of distribution systems to lightning [1]. Waveforms of arrester discharge

PE-376-PWRD-0-12-1997 A paper recommended and approved by the IEEE Surge Protective Devices Committee of the IEEE Power Engineering Society for publication in the IEEE Transactions on Power Delivery. Manuscript submitted August 1, 1997; made available for printing December 12, 1997. currents were recorded for two natural lightning strikes to a $7.62-\mathrm{kV}$ overhead distribution line at unknown distances (although probably very close) from the arresters. One event was a single-stroke flash that lowered negative charge to ground. The arrester discharge current had a peak amplitude of $15 \mathrm{kA}$ with a risetime of about $2 \mu \mathrm{s}$. The other event was a three-stroke flash that lowered positive charge to ground. The peak amplitudes of the arrester discharge currents were $42 \mathrm{kA}, 32 \mathrm{kA}$, and $40 \mathrm{kA}$ for the three strokes, respectively, with risetimes of $5.6 \mu \mathrm{s}$ for the first event and about $1 \mu \mathrm{s}$ for the second and third events.

The Electric Power Research Institute (EPRI) funded a similar arrester study that was carried out from 1987 to 1990 [2]. Waveforms of currents through MOV distribution arresters were recorded for 357 natural lightning flashes, and, in a separate part of the study, waveforms of voltages across MOV distribution arresters were recorded for another 952 flashes. Most of the events recorded were likely induced effects on the distribution line due to nearby lightning strikes to ground. Ninety-five percent of the arrester discharge currents were under $2 \mathrm{kA}$ (peak amplitude) with only three recorded currents exceeding $10 \mathrm{kA}$. A similar percentage of the arrester voltages had peak amplitudes smaller than $17 \mathrm{kV}$ with the largest recorded voltage being about $28 \mathrm{kV}$.

In 1996, during experiments at the International Center for Lightning Research and Testing (ICLRT) at Camp Blanding, Florida [3], we recorded both the lightning discharge currents and voltages for MOV arresters in an unenergized test distribution system. The test system consisted of an overhead line and underground cable, one end of which was attached to the line near its midpoint while the other end was left open-circuited. A padmount transformer was connected to the cable at a distance of 85 meters from the line. Two arresters were installed on the overhead line ( 50 meters apart; one on either side of the strike point), and one arrester was installed at the transformer primary. We obtained arrester data for this test configuration from two lightning flashes (containing a total of five strokes) which were artificially initiated from a natural thunderstorm, using the rocket-and-wire technique [4]. We present the 
simultaneously-recorded arrester discharge current and voltage waveforms from one lightning stroke for one arrester on the line and for the arrester at the transformer primary. Additionally, we estimate the energy absorbed by the arrester on the line as a function of time for the first $4 \mathrm{~ms}$ of the lightning event. The records presented are representative of those from all five strokes.

\section{EXPERIMENTAL SET-UP}

\section{A. Test Distribution System and Rocket-Launching Unit}

An overview of ICLRT, including the general set-up of the test distribution system, is shown in Fig. 1. The overhead line is approximately 730 meters long and supported by fifteen poles. The line consists of two vertically stacked conductors separated by 1.8 meters and mounted on insulators having a critical flashover voltage (CFO) of about $500 \mathrm{kV}$ [5]. The top and bottom conductors simulate the phase and the neutral, respectively, and the line is terminated in its characteristic impedance of $500 \Omega$. The neutral was grounded at Poles 1, 9, 10, and 15. At Poles 9 and 10, General Electric (GE) Tranquell 10-kV MOV distribution arresters were installed between the phase and neutral.

The underground cable is a $15-\mathrm{kV}$ XLPE coaxial cable, approximately 735 meters long, covered with an insulating jacket. The cable was contained in PVC conduit and buried at a depth of 0.9 meters. One end of the cable was attached to the overhead line at Pole 9. A 25-kVA padmount transformer, located in Instrument Station 1 (Fig. 1) with a Cooper Industries $10-\mathrm{kV}$ MOV elbow arrester across the primary, was connected to the cable about 85 meters from the overhead line. The other end of the cable, at Instrument Station 4 (Fig. 1), was left open-circuited. The cable neutral was grounded at both Instrument Stations 1 and 4.

The V-I characterstics, based on $8 / 20 \mu$ s wave, of the GE Tranquell arresters and Cooper elbow arrester are given Table 1 .

The rocket-launching unit shown in Fig. 1 was used to initiate (trigger) lightning via small rockets trailing grounded wires [4]. The launch unit is mounted atop an 11-

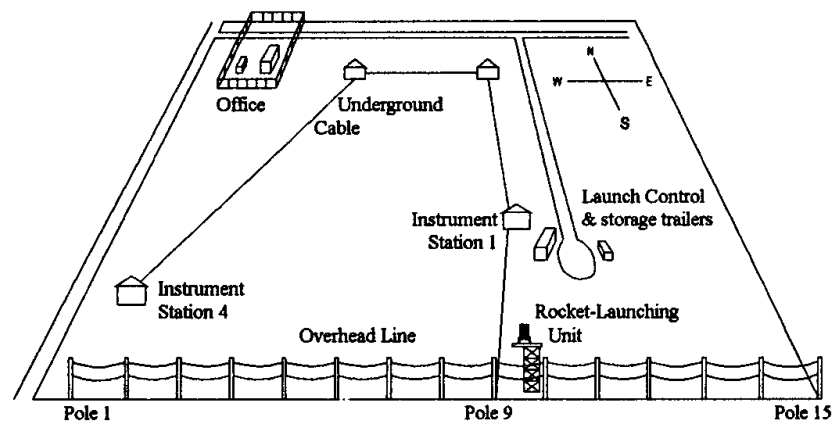

Fig. 1. Overview of the International Center for Lightning Research and Testing (ICLRT) at Camp Blanding, Florida. meter tower located 20 meters north of the overhead line, between Poles 9 and 10 . The triggered-lightning current was directed from the launch unit to the overhead line by means of a metal cable which was connected to the phase conductor of the line between Poles 9 and 10.

\section{B. Instrumentation and Measurement Locations}

The discharge currents were measured at each arrester with 16.5-m $\Omega$ current viewing resistors (shunts) and were recorded with Macrodyne Lightning Transient Recorders (LTRs). LTRs are single-channel recorders with 7-bit amplitude resolution (128 quantization levels) and 5 MHz sampling rate. The effective sampling rate at which data are actually stored into memory is variable [2], depending on the rate of change of the input signal. Portions of the signal with higher rates of change will be stored into memory at a rate up to $5 \mathrm{MHz}$, while portions of the signal with lower rates of change will be stored into memory at a lower rate. When the input signal is zero or nearly $\mathrm{DC}$, the rate is a minimal $76 \mathrm{~Hz}$. This memorysaving mode of operation allows a record length of $1 \mathrm{~s}$. LTRs are battery powered and mounted in shielding containers at the measurement locations. These recorders do not have pre-trigger memory nor can they be triggered externally. Trigger thresholds are set individually, and thus, LTRs trigger independently of one another. The memory content of each LTR is accessed with a portable (lap-top) PC via a fiber optic interface. The alignment of LTR data is done after the data have been recorded, by examining the entire waveform of each data file and identifying common features in different data records.

The voltages were measured between the phase and neutral conductors at the arrester locations (except at Pole 10) with resistive voltage dividers and were recorded with Nicolet Pro 90 digitizing oscilloscopes at a $10 \mathrm{MHz}$ sampling rate. The Nicolet Pro 90 is a four-channel recorder with an amplitude resolution of 8-bit (256

Table 1

V-I Characteristics of the $10-\mathrm{kV}$ MOV Arresters (8/20 $\mu$ s wave)

\begin{tabular}{|c|c|c|}
\hline \multirow{2}{*}{$\begin{array}{c}\text { Discharge } \\
\text { Current }[\mathrm{kA}]\end{array}$} & \multicolumn{2}{|c|}{ Discharge Voltage [kV] } \\
\cline { 2 - 3 } & GE Tranquell & Cooper Elbow \\
\hline 0.001 & 18.1 & - \\
\hline 0.01 & 18.9 & - \\
\hline 0.1 & 20.6 & - \\
\hline 1 & 23.4 & - \\
\hline 1.5 & 24.4 & 28.4 \\
\hline 3 & - & 30.6 \\
\hline 5 & - & 32.9 \\
\hline 10 & 29.6 & 36.7 \\
\hline 20 & 33.2 & 40.4 \\
\hline 50 & 38.6 & - \\
\hline
\end{tabular}


quantization levels) for channels 1 and 2 and 12-bit (4096 quantization levels) for channels 3 and 4 . It has pre-trigger memory capability, which was set to $0.5 \mathrm{~ms}$. Post-trigger delay was used to set channels 1 and 2 to record sequentially and channels 3 and 4 to record sequentially. Combining the channels allowed a 52-ms record length for each voltage measurement. The Nicolet Pro 90 oscilloscopes were housed in the Launch Control trailer (Fig. 1) and measured the output signals of the voltage dividers remotely via Nicolet Isobe 3000 fiber optic links, each composed of an Isobe transmitter, a fiber optic cable, and an Isobe receiver. The transmitters are battery powered and mounted in shielding containers at the measurement locations. The transmitter output signal propagated along optical fibers to the receivers which were housed with the oscilloscopes in the Launch Control trailer.

The total triggered-lightning current was measured at the launch unit with a $1-\mathrm{m} \Omega$ shunt and three current transformers (CTs). Multiple sensors were used at the launcher to increase the dynamic range of the measurements and for redundancy. The shunt's output was relayed via two Nicolet Isobe 3000s (having different gains) and recorded with Nicolet Pro 90 oscilloscopes located in the Launch Control trailer. One Isobe $3000 \mathrm{had}$ a measurement range of $+/-50 \mathrm{kA}$ and a sampling rate of $20 \mathrm{MHz}$ to capture the impulsive stroke currents; and the other had a measurement range of $+/-5 \mathrm{kA}$ and a sampling rate of $0.5 \mathrm{MHz}$ to capture low-level, continuing currents. The outputs of the current transformers were measured with LTRs (although only one CT was instrumented with an LTR for the tests presented here). The Nicolet measurements were synchronized by means of a master/slave triggering mode. The master oscilloscope triggers internally on the measured lightning current at the launcher and sends a TTL (transistor-transistor logic) pulse to trigger externally the slave oscilloscopes measuring arrester discharge voltages. The data records from all the Nicolet oscilloscopes were stored on a PC hard drive.

\section{DATA AND ANALYSIS}

Simultaneous arrester discharge current and voltage waveshapes were obtained from two artificially-initiated lightning flashes (9631 and 9632), both lowering negative charge to ground. Flash 9631 was a four-stroke flash, and Flash 9632 was a single-stroke flash. Due to the shorter recording length of the Nicolet Pro 90 digitizing oscilloscopes, arrester voltages are not available for strokes three and four of Flash 9631. The data presented in this paper are for the single stroke of Flash 9632. Those data are characteristic of the overall data set [3].

Although the voltage and current waveforms presented in the following figures correspond to the same lightning event, they were recorded independently (see Section II-B) and aligned manually using the peak amplitude as a guide. The amplitudes of all currents and voltages shown in Figs. 2, 3, and 4 are of negative polarity, which corresponds to negative charge being lowered to ground by the lightning flash. Thus, in the following analysis, when the term "increase" or "rise to crest" is used, it is in reference to the signal amplitude increasing in its negative value.

The total lightning current $(+/-50 \mathrm{kA}$ measurement range) measured at the rocket launching-unit for Flash 9632 along with the corresponding responses of the MOV arrester

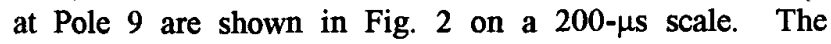
lightning current in Fig. 2a has a peak value of about $12 \mathrm{kA}$, a 10 to $90 \%$ risetime of $0.5 \mu \mathrm{s}$, and a half-peak width of about $15 \mu \mathrm{s}$. These values are typical of subsequent strokes in natural lightning [6]. First strokes in natural lightning have peak current values two to three times larger [7]. The arrester discharge current in Fig. $2 \mathrm{~b}$ has a peak value of 3.6 $\mathrm{kA}$ with a 10 to $90 \%$ risetime of about $0.4 \mu \mathrm{s}$ and half-peak width of about $60 \mu \mathrm{s}$. We observe that the peak discharge current at Pole 9 is $30 \%$ of the total peak lightning current and that the arrester current decays slower than the lightning current. Although poorly resolved, there are small oscillations superimposed on a slower current of opposite polarity preceding the negative arrester discharge current, a feature previously observed by Barker et al. [2]. After 200 $\mu \mathrm{s}$, the arrester current approaches the resolution limit of the data recorder.

The arrester voltage in Fig. 2c has a large spike at the beginning presumably due to inductance of the arrester lead which was about $1.4 \mathrm{~m}$ in length, but possibly also containing a contribution from magnetic coupling to the wiring of the voltage divider circuit. The voltage spike is observed to have a 10 to $90 \%$ risetime of $0.4 \mu \mathrm{s}$, and a halfpeak width of $0.3 \mu \mathrm{s}$. After the spike, the arrester clamps the voltage on a slope, decaying from $25 \mathrm{kV}$ to $21 \mathrm{kV}$ in this plot, which is consistent with the V-I characteristic for the GE arresters given in Table 1.

Fig. 3 shows the responses of the MOV elbow arrester at the transformer primary, which are more complex than the arrester responses shown in Fig. 2. The arrester discharge current in Fig. 3a has an initial crest of $860 \mathrm{~A}$ and a 10 to $90 \%$ risetime to this peak of about $0.4 \mu \mathrm{s}$. The current then exhibits damped oscillations with a period of 1.8 $\mu \mathrm{s}$. This is consistent with wave reflections between Instrument Station 1 and Pole 9 (85 meters apart) for a propagation speed of about one-quarter to one-third the speed of light. About $10 \mu \mathrm{s}$ later, the arrester current rises to another crest which was clipped (for only a few data samples) at the data recorders' upper measurement limit of $1.1 \mathrm{kA}$ and was followed, similar to the first crest, by oscillations with a period of about $1.6 \mu \mathrm{s}$. The current waveform then exhibits progressively smaller crests separated by about $19 \mu \mathrm{s}$. The successive crests are probably indicative of wave reflections between Pole 9 and Instrument Station 4 ( 735 meters apart). After $100 \mu \mathrm{s}$, the arrester current approaches the resolution limit of the data recorder.

The arrester voltage at the transformer primary is shown in Fig. 3b. The voltage shows successive crests 

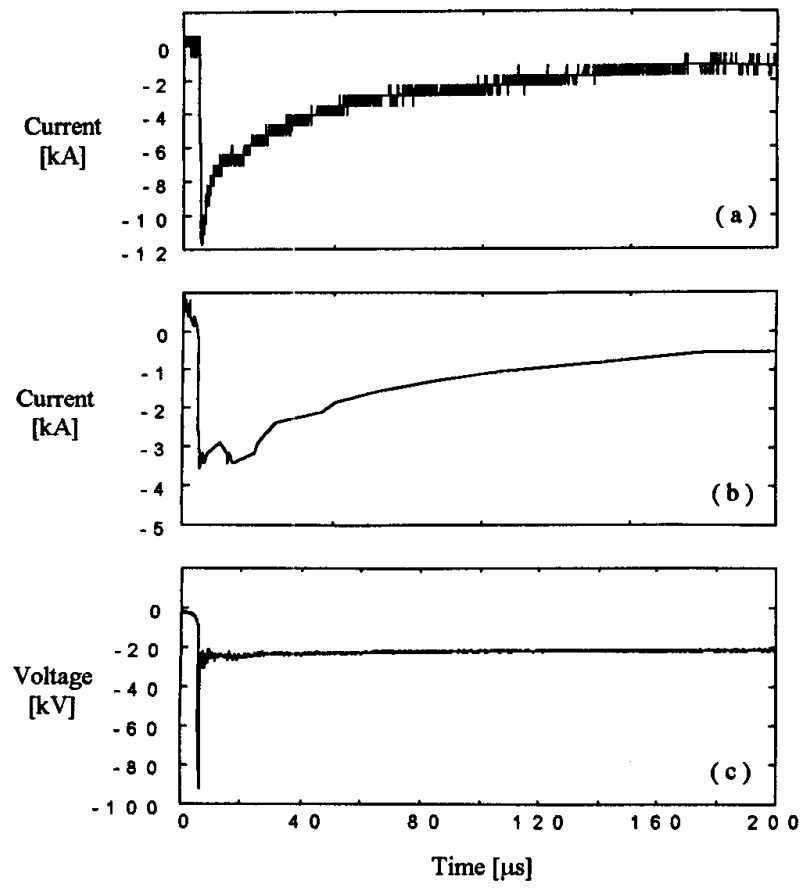

Fig. 2. Responses of the MOV arrester at Pole 9, displayed

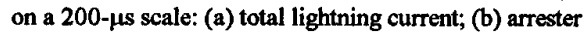
discharge current; (c) arrester voltage.
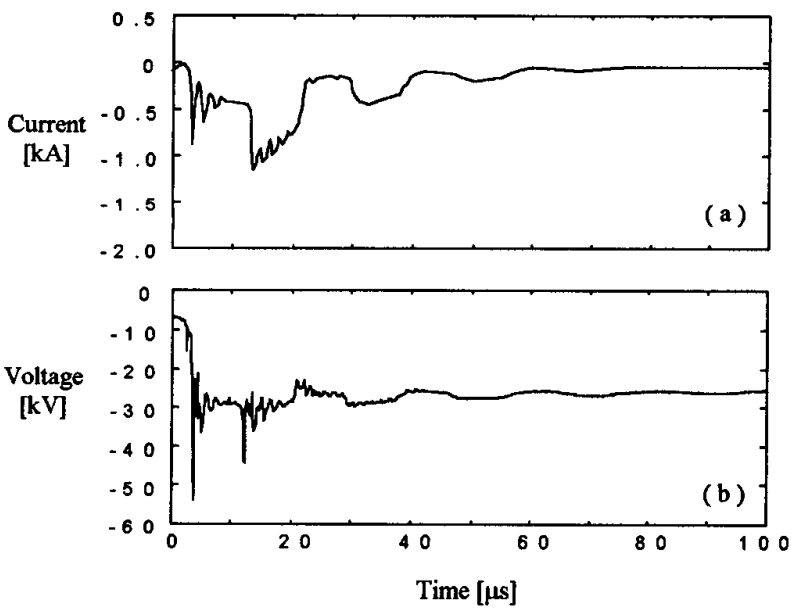

Fig. 3. Responses of the MOV elbow arrester at the transformer primary, displayed on a 100-us scale: (a) arrester discharge current; (b) arrester voltage.

(similar to those in the current record) with large spikes at the initial portions of the first two. The voltage spikes are observed to have 10 to $90 \%$ risetimes of $0.8 \mu \mathrm{s}$ and $0.3 \mu \mathrm{s}$, respectively, and half-peak widths of $0.4 \mu \mathrm{s}$. The arrester holds the voltage around $26 \mathrm{kV}$ or so, including a dc offset of about $7 \mathrm{kV}$ seen before the initial rise to crest.

From Figs. $2 c$ and $3 b$, we observe the voltage clamping operation of the arresters on a relatively short time
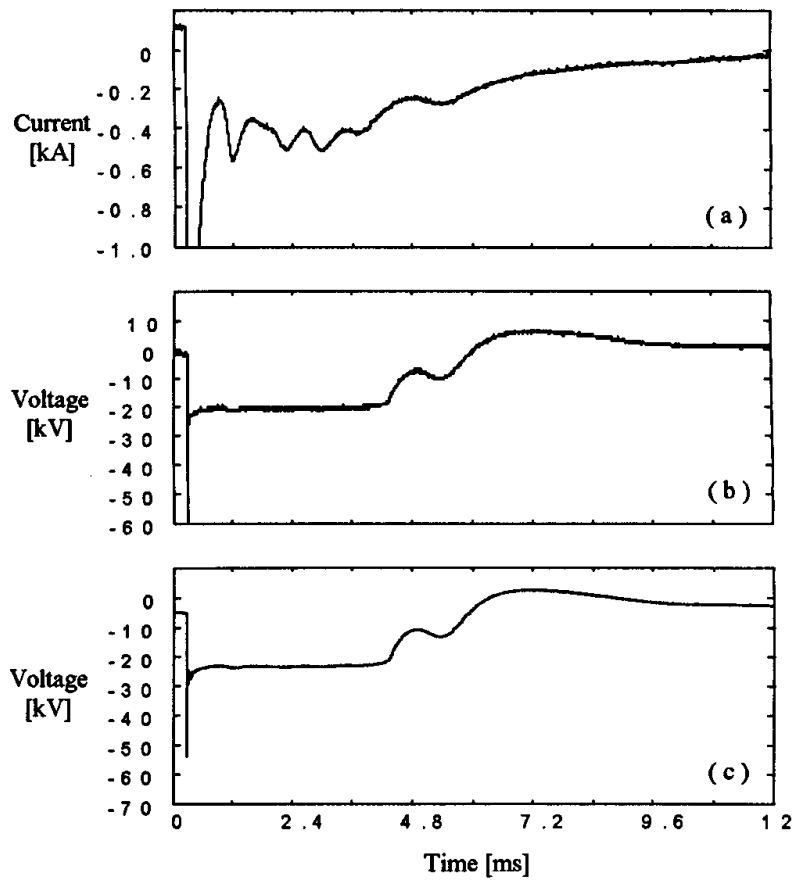

Fig. 4. (a) The low-level lightning current at the rocketlaunching unit [shown clipped at $1 \mathrm{kA}$ ]; (b) arrester voltage at Pole 9 [shown clipped at $60 \mathrm{kV}$; (c) arrester voltage at the transformer primary, each displayed on a $12-\mathrm{ms}$ scale.

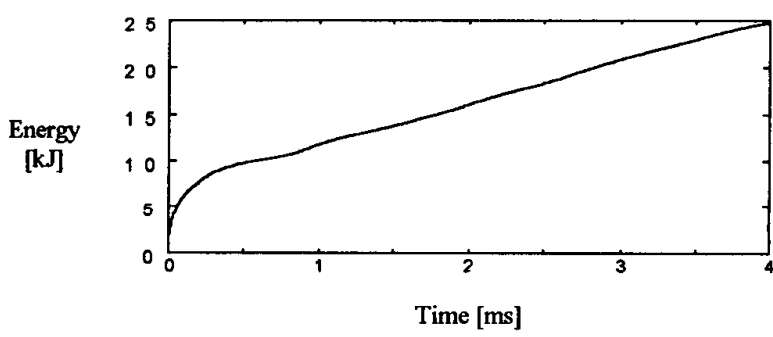

Fig. S. Estimated energy absorption by the MOV arrester at Pole 9.

scale (hundreds of microseconds). The voltage response of the arresters (and the total lightning current) are of much longer duration than the resolvable discharge current. Fig. 4 shows the total lightning current (Fig. 4a) and the arrester voltages at Pole 9 (Fig. 4b) and at the transformer primary (Fig. 4c) on a 12-ms scale. In Figs. $4 b$ and $4 c$, we see that the voltages are clamped near $20 \mathrm{kV}$ and $23 \mathrm{kV}$, respectively, for about $4 \mathrm{~ms}$, then begin to return to their background levels. The falling trend of the waveforms is interrupted, and both voltages exhibit a hump with amplitude of about $3 \mathrm{kV}$. (A similar feature is also seen in the waveshape of the total lightning current in Fig. 4a.) After the hump, the voltages further decrease, cross their background levels, and produce an opposite polarity overshoot lasting several milliseconds. The overshoots have peak values of about $8 \mathrm{kV}$ (measured relative to the background levels). No overshoots 
are observed in the arrester current records. From the arresters' V-I characteristics in Table 1 , corresponding overshoots in the arrester discharge currents, if present, would have been below the resolution limit of their respective data recorders.

The total lightning current $(+/-5 \mathrm{kA}$ measurement range) in Fig. 4a is included because this was the only current measurement available that had sufficient amplitude resolution over the 12-ms sweep. It should be noted, though, that this current is the total current entering the test system, which is shared among the two arresters and two terminating resistors on the overhead line, the elbow arrester, and the transformer primary, not the discharge current of an arrester. Nevertheless, the results are interesting because we observe that the initial return-stroke current pulse (shown clipped at 1 $\mathrm{kA})$ was followed by five smaller current pulses, ranging from tens to hundreds of amperes, riding on the low-level continuing current. The first four pulses occurred during the voltage-clamping operation of the arresters and resulted in little or no observable change in the arrester voltages. The fifth current pulse, however, occurred during the falling edge of the voltage waveforms and produced the $3-\mathrm{kV}$ increase in the arrester voltages described in the preceding paragraph, with the amplitude of the pulse in the lightning current being as low as $40 \mathrm{~A}$ or so.

At $200 \mu \mathrm{s}$, the arrester discharge current (Fig. 2b) is about one-half of the total lightning current (Fig. 2a). Thus, if we assume that the same fraction (one-half) of the lightning current in Fig. 4a is flowing through the arrester at Pole 9 after $200 \mu \mathrm{s}$ and is causing the voltage response in Fig. $4 b$, we can estimate the energy absorption by the arrester at Pole 9 as a function of time, shown in Fig. 5. In Fig. 5, we observe that the energy absorbed during the initial $200 \mu \mathrm{s}$ is about $8 \mathrm{~kJ}$ or about one-third of the total energy of $25 \mathrm{~kJ}$ absorbed during the voltage-clamping stage of the arrester operation lasting $4 \mathrm{~ms}$ or so.

For GE Tranquell MOV arresters, the maximum energy capability is $4.0 \mathrm{~kJ} / \mathrm{kV}$ of rating [8] or $40 \mathrm{~kJ}$ for this case. Therefore, during the first $4 \mathrm{~ms}$ of the event considered here, the arrester was subjected to about $60 \%$ of its maximum energy capability. Video and photographic records, along with visual inspection, indicate that physical damage was not sustained to any of the MOV arresters as a result of the tests. Further evidence for this fact can be found in the similar current and voltage records from the five strokes of the two triggered lightning flashes, the final one of which being presented in this paper.

\section{ACKNOWLEDGMENTS}

The 1996 Camp Blanding experiments were conducted with the participation of M. Darveniza, T.W. Vaught, M.V. Stapleton, G.H. Schnetzer, and A. Staley and were supported by the Electric Power Research Institute (Project Manager R. Bernstein), Duquesne Light Co. (Project Manager J.L. Koepfinger), the Florida Power Corporation
(Project Manager C.W. Williams), the National Science Foundation (Program Director R.C. Taylor), and the National Aeronautics and Space Administration (W. Jafferis).

\section{REFERENCES}

1. H.M. Schneider and H.R. Stillwell, "Measurement of Lightning Current Waveshapes on Distribution Systems", IEEE PES Summer Meeting, Paper A 79 526-5, July 15-20, 1979.

2. P.P. Barker, R.T. Mancao, D.J. Kvaltine, and D.E. Parrish, "Characteristics of Lightning Surges Measured at Metal Oxide Distribution Arresters", IEEE Trans. Power Delivery, vol. 8, no. 1, January 1993, pp. 301-310.

3. M.I. Fernandez, "Responses of an Unenergized Test Power Distribution System to Direct and Nearby Lightning Strikes", Master's thesis, University of Florida, Gainesville, 1997.

4. M.A. Uman, V.A. Rakov, K.J. Rambo, T.W. Vaught, M.I. Fernandez, D.J. Cordier, R.M. Chandler, R. Bernstein, and C. Golden, "Triggered-Lightning Experiments at Camp Blanding. Florida (1993 - 1995)", Trans. IEE Japan, Special Issue on Artificial Rocket Triggered Lightning, vol. 117-B, no. 4, 1997, pp. 446-452.

5. P.P. Barker, T.A. Short, A.R. Eybert-Berard, and J.P. Berlandis, "Induced Voltage Measurements on an Experimental Distribution Line During Nearby Rocket Triggered Lightning Flashes", IEEE Trans. Power Delivery, vol. 11, no. 2, April 1996, pp. 980-995.

6. R.J. Fisher, G.H. Schnetzer, R. Thottappillil, V.A. Rakov, M.A. Uman, and J.D. Goldberg, "Parameters of Triggered-Lightning Flashes in Florida and Alabama", J. Geophys. Res., vol. 98, no. D12, December 20, 1993, pp. 22887-22902.

7. M.A. Uman, The Lightning Discharge. Orlando: Academic Press, 1987.

8. A. Greenwood, Electrical Transients in Power Systems, $2^{\text {nd }}$ Ed. New York: John Wiley \& Sons, 1991.

\section{BIOGRAPHIES}

Mark I. Fernandez received his Bachelor's degree from Florida Institute of Technology (FIT), Melbourne in 1995 and is expected to receive his Master's degree from the University of Florida (UF), Gainesville in 1997. Mr. Fernandez was involved in magnetospheric and space plasma research as an undergraduate in the Department of Physics and Space Sciences at FIT. Since 1995 he has held a graduate research assistantship in the UF Lightning Research Laboratory. $\mathrm{He}$ has co-authored three papers published in reviewed journals and has authored or co-authored eight published abstracts or conference proceedings and a technical report. Mr. Fernandez is a student member of the American Geophysical Union, Florida Academy of Sciences, and IEEE.

Kelth J. Rambo received the B.S.E.E. degree from the University of Florida (UF) in 1978. As an undergraduate he worked in the UF Lightning Research Laboratory. From 1979 to 1983 he was Senior Process Engineer of Intel Corporation in Santa Clara, California, and from 1983 to 1985 he was Product Line Manager of Xicor Inc. in Milpitas, California. In 1986, he joined the UF Department of Electrical and Computer Engineering where since 1989 he has been Director of Technical Support Services. Since 1994, Mr. Rambo has been heavily involved in triggered-lightning experiments at Camp Blanding, Florida. He has 10 technical publications.

Vladimir A. Rakov received the Master's and Ph.D. degrees from Tomsk Polytechnical University (Tomsk Polytechnic), Russia in 1977 and 1983, respectively. From 1977 to 1979 he worked as an Assistant Professor of Electrical Engineering at Tomsk Polytechnic. In 1978 he became involved in lightning research at the High Voltage Research Institute, a division of Tomsk Polytechnic, where, since 1984, he has held the position of Director of the Lightning Research Laboratory. He has been named an Inventor of the USSR (1986) and received a Silver Medal from The (USSR) National Exhibition of 
Technological Achievements (1987). During 1988-1989 he spent a 10-month sabbatical at the University of Florida's (UF) Lightning Research Laboratory. Since 1991, he has held the position of Associate Professor of Electrical and Computer Engineering at UF. Dr. Rakov is a member of the American Geophysical Union (AGU), the AGU Committee on Atmospheric and Space Electricity, the American Meteorological Society, the CIGRE Working Group 33.01 "Lightning", and a Senior member of IEEE. He is author or coauthor of over 30 patents and over 120 papers on various aspects of lightning, over 50 of them in reviewed journals.

Martin A. Uman is professor and chair of the University of Florida's Department of Electrical and Computer Engineering. Dr. Uman has written 3 books on the subject of lightning (two now in revised second editions), as well as a book on plasma physics, ten book chapters and encyclopedia articles on lightning, and has published over 130 papers in reviewed journals and over 140 articles and reports in unreviewed publications. He holds 5 patents, 4 in the area of lightning detection.
Dr. Uman received his bachelor's, master's and doctoral degrees from Princeton University, the latter in 1961. He was an associate professor of electrical engineering at the University of Arizona in Tucson from 1961 to 1964. Dr. Uman joined the University of Florida faculty in 1971 after working for seven years as a Fellow Physicist at Westinghouse Research Labs in Pittsburgh. Dr. Uman co-founded and served as president of Lightning Location and Protection, Inc. (LLP) from 1975 to 1983.

Dr. Uman is the recipient of the 1996 IEEE Heinrich Hertz Medal for... "outstanding contributions to the understanding of lightning electromagnetics and its application to lightning detection and protection." Dr. Uman was named the 1990 Florida Scientist of the Year by the Florida Academy of Sciences. Honored as 1988-89 University of Florida TeacherScholar of the Year, the highest UF faculty award, he is a Fellow in three professional organizations: the American Geophysical Union (AGU), the American Meteorological Society (AMS), and the Institute of Electrical and Electronics Engineers (IEEE). Other awards include NASA's 1992 Group Achievement Award to the Galileo Probe Spacecraft Team. 


\section{Discussion}

R. A. WALLING (GE Power Systems Energy Consulting, Schenectady NY) The triggered lightning, described in this paper, exhibits both high-frequency (impulsive currents) and low-frequency (continuing current) components. This is consistent with the characteristics of natural lightning. To be a valid rendition of the phenomena taking place in actual power distribution systems, the test system must exhibit realistic impedance characteristics over the whole frequency range. Surge impedance termination of the short-length test line provides valid impedance characteristics for the impulsive currents. They do not, however, represent a realistic termination impedance for low-frequency continuing currents.

In an actual (grounded) system, continuing currents will tend to flow into the system as a whole, finding their way to ground throughout the system. The effective impedance of the system is the line-to-ground short-circuit impedance at each frequency component of the continuing current. Because of the much lower impedance of the system to the low-frequency continuing currents, compared to an arrester, very little of the continuing current would normally be discharged by the arrester. The authors results, however, show that two thirds of the arrester energy is due to the continuing current. In the opinion of this discusser, this is unrealistic except in ungrounded distribution systems

Connection of an inductor in parallel with the surge resistor at one test line termination, with the inductance consistent with the typical short-circuit inductance seen on a typical distribution circuit, would be much more accurate. Would the authors please comment on the validity of the termination impedance of the test line with respect to continuing currents?

V.A. Rakov, M.A. Uman (University of Florida, Gainesville, FL): The discusser suggests that the results on energy dissipation by arresters (to a large extent due to the continuing current) presented in the paper might be irrelevant to an actual grounded power distribution system because, in his opinion, in such a system negligible lower-frequency continuing current would flow through the arresters. We state in response that a significant lower-frequency current flowing through a $10 \mathrm{kV}$ MOV arrester in an actual four-wire multigrounded power distribution system has been documented by Barker et al. (1993) (Reference [2] of the paper). In their Fig. 11 , they show the arrester discharge current, recorded in an actual power system, that exhibits a slow tail lasting for the $2 \mathrm{~ms}$ duration of the presented trace at an average level of about $2 \mathrm{kA}$. It is important to note that the total duration of this current is longer than $2 \mathrm{~ms}$, considering the slope of the current wave at the end of the trace and the instrument's amplitude resolution of about 200 A. Assuming a clamping voltage of 20 $\mathrm{kV}$ and a conservative duration of $2 \mathrm{~ms}$, we estimate the energy dissipated by the arrester to be about $80 \mathrm{~kJ}$. This energy is associated only with the lower-frequency current components and apparently represents the bulk of the total stroke energy dissipated by the arrester, similar to the example given in our paper. Therefore, the discusser's assertion that our results are relevant only to ungrounded distribution systems appears to be incorrect.

On the other hand, the question raised by the discusser leads to a more general question: what factors determine the division of the lightning current between the many paths to ground available in actual systems? Clearly, this division is different for the different frequency components (from near d.c. to over $1 \mathrm{MHz}$ ) present in the lightning current. These factors include, but are not limited to, the position of the strike point, the number of arresters sharing the current, the grounding, the length and terminations of the overhead line (the element of a power system which is most often struck by lightning), and the presence of transformers and underground cables attached to the overhead line. In our paper, we present only one example for a single test-distribution-system configuration. Several additional cases are described in detail in Reference [3] of the paper and will be presented in the following journal publications, with the results both providing some additional insights into the current division issue and raising new questions. In one of the triggered-lightning tests, MOV arresters were installed on Poles 1, 9, 10, and 15 with the underground cable not connected to the overhead line (see Fig. 1 of our paper). Lightning current was injected into the phase conductor between Poles 9 and 10. The arrester at Pole 10 failed during the initial continuous current resulting in a significant reduction of the duration of the voltage clamping plateau for the remaining three arresters (at Poles 1, 9, and 15) during the following stroke compared to measurements in tests with no arrester failures. It appears that the failed arrester served to drain the lower-frequency current components from the phase conductor while having apparently little effect on the higher frequency components during the first some tens of microseconds of the return stroke. A similar effect is predicted by EMTP for the case of an inductor connected in parallel with one of the termination resistors, the distribution system model suggested by the discusser.

Finally, we would like to point out that the experimental data obtained for our test distribution system are presently being used to 
calibrate an EMTP model of the system. The results of the EMTP modeling and more experimental data for different system configurations and different positions of the lightning strike point will be presented in future papers. The authors would like to thank Carlos $\mathrm{T}$. Mata for the EMTP simulations and for many helpful discussions. 